\title{
Nudging and the Ecological and Social Roots of Human Agency
}

\author{
by Nicolae Morar and Daniel Kelly ${ }^{1}$
}

\section{Introduction}

Those crafting healthcare policies must struggle with the dire medical reality that nearly 22 people die every day while waiting for an organ transplant (USDHHS 2016). MacKay and Robinson's (M\&R) article addresses ethical questions raised by the ways different choice architectures present people with options concerning how they might help improve this situation by donating their own organs after they die. Their main conclusions are that all four choice architectures that they consider are pro tanto morally wrong, and that each fails, ultimately, because it does not respect the autonomy of those being presented with the choice.

For the sake of a clean dialectic, we advance an argument we are tempted but not yet fully convinced by, or at least formulate our response in terms that are starker than we would otherwise. We take the conclusion that none of the four considered choice architectures is morally permissible to be unacceptable, and so interpret the argument that produced it as a reductio ad absurdum. Consequently, we attempt to identify which premise in the authors' line of reasoning is the culprit that leads to the unacceptable conclusion.

\section{Coercion and Default Rules}

That none of the four options for asking people about organ donation js morally acceptable strikes us as implausible. While the final assessment as pro tanto morally deficient is uniform across all four options, their flaws divide them into two categories those that are putatively coercive and those that use a form of putatively reason-bypassing nonargumentative influence.

\footnotetext{
1 Address correspondence to Daniel Kelly, Department of Philosophy, 100 N University Street, Purdue University, West Lafayette, IN, 47907, USA. E-mail: drkelly@purdue.edu
} 
The authors find fault in mandated active choice (MAC) options for being coercive. More specifically, they object to the fact that MACs "require" people "to register as organ donors or not" (20) and impose sanctions on those failing to meet this obligation (8). Here we think M\&R overplay their hand. In general, categorizing as "coercion" the mere act of addressing someone with a question is a stretch of the intuitive concept. Describing MACs as also "forcing" $(8,22)$ people to choose between pre-established response options can lessen this impression, but we think even this description is misleading. After all, one doesn't absolutely have to answer the question if one doesn't want, e.g. on pain of incarceration or death. There is no forcing in this case, but rather a (to us, reasonable) tradeoff: one has the option to not answer, but exercising that option is not without consequences. One can refuse, and live without a driver's license. That's the price one pays; such is the way of society, life lived with the comforts and benefits of a social contract. Perhaps merely answering such questions carries some cost - though we do not share the libertarian flavored intuition the authors express (22), and would resist saying that the cost was a moral one. But describing as "coercion" the fact that claiming one privilege (e.g. getting a driver's license) is conditional on merely having to answer a question extends the concept of coercion beyond its useful limits.

Moving on to the other three nudges, M\&R point out that voluntary active choice (VAC), opt-in, and opt-out varieties each employ a particular default rule that frames how questions and options about organ donation are put to people, and that specifies (often implicitly) what happens if people remain passive, making no active change to the frame. Policy makers like default rules because they have predictable influence over collective outcomes. At the individual level, psychologists are still debating which cognitive mechanisms mediate the influence of what types of nudges, and how. M\&R criticize these three nudges for the kind of influence they allegedly exert, seeing it as a threat to our autonomy; it is, they claim, reason-bypassing and non-argumentative. While we reject this characterization as overly simplified (e.g. human reason, rationality, and argumentation are not confined to the slow, deliberate, linguistic, propositional, explicit, or syllogistic, and may not even have evolved to arrive at truth or make good decisions, but to do something more social, namely persuade (Mercier and Sperber 2011)), we will instead elaborate on another point. As the authors recognize (13), psychological details about how and how much a 
default rule influences individual level decision-making are relevant to their argument. However, many of those psychological details remain murky.

For instance, if the putatively autonomy-corrupting power of default rules stemmed, as M\&R's criticism suggests, from a lack of transparency, or from how they evaded the awareness or rational capacities of the decisions makers they were presented to, we should expect that when the presence of those rules and details about how they operate are made explicit in the choice architecture itself, or when choosers are pre-informed about those details, the effectiveness of the nudge would drop off. Even on M\&R's austere conception of reason, reason would be addressed rather than bypassed by such additions. However, Lowenstein et al (2015) report results contrary to this expectation. In a study concerning decisions about advanced medical directives, they show that "fuller disclosure of a nudge could potentially be achieved with little or no negative impact on the effectiveness of the intervention" (36). In other words, the effectiveness of a nudge is not a simple function of its bypassing reason, but is more complicated, and potentially less morally objectionable, even on M\&R's own terms. Obviously this study is not the last word, but it calls into question the quick dismissal of nudges based on simple pictures of how they engage, or fail to engage, certain parts of our psychology.

\section{Moral Ecology and the Sociality of Agency}

Beyond these more specific objections, we believe the picture of autonomy and agency that M\&R work with represents the reductio premise from which their argument's (to us) unacceptable conclusion ultimately flows. We thus end by sketching an alternative way to conceive of agency that is finding traction in the work of philosophers attuned to recent advances in empirical moral psychology, and that highlights the deeply ecological and social roots of human autonomy.

$\mathrm{M} \& \mathrm{R}$ work with an "intentionally generic ... conception of autonomy that emphasizes the role of critical or rational reflection". This, and the rest of their discussion, places great emphasis and value on explicit, internal cogitation, and suggests a pristine image of autonomy as a state that an individual agent possesses, and realizes most fully and purely when she is alone, perhaps in a quiet room, undisturbed by social interactions, safely 
protected from corrupting environmental influences. Others have marshaled evidence against the family of "reflectivist" views of agency associated with M\&R's reflection-based conception of autonomy, arguing that such views do not accurately capture how people's values and preferences are expressed in their behaviors, and so would have the undesirable result of making instances of autonomous action and genuinely agency empirically extremely rare (Doris 2015). The alternatives are messier, but a range of recent empirical work illustrates ways in which human behavior, including moral behavior, is dialogic, and deeply relies on situational, environmental, cultural and social factors (Doris and Nichols 2012). Central to this picture are social norms, especially those that govern the practices of holding people morally responsible for behaviors (Washington and Kelly 2016). These help make up the "moral ecology," that part of the cultural and cognitive niche that help support and enable action and guide exercises of responsible agency (Vargas 2013).

Closer to home here, bioethicists have built the canon of autonomy on a pillar of individualism and on its successful expression as resistance to outside influences. However, work in the feminist tradition also militates against the view that 'optimal moral reasoning' is realized against social inputs, and suggests that complex moral cognition and multifaceted policy analysis emerge as a function of our sociality (Beever and Morar 2016). It also suggests that our moral judgments, our values and autonomy are typically better expressed when they are socially embedded. This view is built on a revised conception of human nature de-emphasizes the importance of explicit deliberation, but also recognizes the extent to which human agents themselves extend beyond biological and cognitive boundaries as 'distributed, hybrid-problem solving ensembles' (Clark 2007) for whom autonomy largely amounts to managing, calibrating, and refining the niches in which they live.

The relevant upshot of all this is that agency and autonomy are intrinsically social, and are often built with, and are inseparable from, interactions with others that take place in cultural environments and moral ecologies that we ourselves construct. We unavoidably operate in the midst of all sorts of environmental and social influences; as Sunstein (2014) puts it "Nature itself nudges; so does the weather; so do customs and traditions; so do spontaneous orders and invisible hands. The private sector inevitably nudges, as does the government" (1). These influences, we suggest, do not corrupt or compromise our agency and autonomy; they help create and sustain them, and navigating those influences is what 
autonomy and agency are for. Anyway, there is no escaping them, so better to use this slowly dawning understanding of our selves and situation not just to distract and titillate, but to promote some worthwhile ends as well.

\section{References}

1. Beever, J. \& Morar, N. 2016. "The Porosity of Autonomy: Social and Biological Constitution of the Patient in Biomedicine," American Journal of Bioethics, 16(2):34-45

2. Clark, A. 2007. "Soft Selves and Ecological Control," in D. Spurrett, D. Ross, H. Kincaid and L. Stephens (eds) Distributed Cognition and the Will. Cambridge, MA: The MIT Press.

3. Doris, J. 2015. Talking to Ourselves: Reflection, Ignorance, and Agency. Oxford University Press.

4. Doris, J. and Nichols, S. 2012. "Broadminded: Sociality and the Cognitive Science of Morality." In E. Margolis, R. Samuels, and S. Stich (eds.), The Oxford Handbook of Philosophy and Cognitive Science, pp. 425-53. Oxford: Oxford University Press

5. Loewenstein, G., Cindy Bryce, David Hagmann, \& Sachin Rajpal. 2015. "Warning: You are about to be nudged," Behavioral Science and Policy, 1(1): 35-42

6. Mercier, H. and Sperber, D. 2011. "Why do humans reason? Arguments for an argumentative theory," Behavioral and Brain Sciences, 34: 57 - 111.

7. Sunstein, C. 2014. "The Ethics of Nudging" (working paper), available at: http://papers.ssrn.com/sol3/papers.cfm?abstract_id=2526341

8. US Department of Health and Human Services. 2016. Available at: https://optn.transplant.hrsa.gov/

9. Vargas, M. (2013). Building Better Beings: A Theory of Moral Responsibility. Oxford: University Press.

10. Washington, N. and Kelly, D. (2016). 'Who's Responsible for This? Moral Responsibility, Externalism, and Knowledge about Implicit Bias,' Implicit Bias and Philosophy, Vol.2. Eds. M. Brownstein and J. Saul. New York: Oxford University Press. Pages 12-36. 